\title{
Evaluasi Sertifikasi Green Building pada Gedung Institut Teknologi \& Sains Bandung
}

\author{
Siti Mega Rosalia ${ }^{1}$, Annisa ${ }^{1}$, Siswanti Zuraida ${ }^{1}$ \\ Teknik Sipil, Teknik dan Desain, Institut Teknologi dan Sains Bandung, Bekasi, Indonesia \\ E-mail: megarosalia97@gmail.com
}

Informasi naskah:

Diterima

10 Juli 2020

Direvisi

10 Agustus 2020

Disetujui terbit

20 Agustus 2020

Diterbitkan

31 Agustus 2020

\begin{abstract}
Global warming is one of the world's prominent issue that related to the environment. As a support to reduce the causes of global warming, Institut Teknologi dan Sains Bandung (ITSB) has applied a concept of green building and got the greenship building's certificate since 2013 2016 with the result score was 64 points or gold category of Green Building of Council Indonesia (GBCI). This study aims at evaluating the existing building of ITSB for knowing the new result score of greenship building's certification. This results score can be a simple directive for ITSB to do the new certification. The collecting data that used were partisipative observation, interview, and quisionnaire as the primary data and literature as the secondary data. The evaluative-descriptive qualitative methods was used to analyze data. The evaluating of Greeship Existing Buildings using an assessment from GBCI with 6 parameters, those parameters are Approprite Site Developent (ASD), Energy Efficiency and Conservation (EEC), Water Conservation (WAC), Material Resource and Cycle (MRC), Indoor Health and Comfort (IHC), and Building Environmental Management (BEM). The result of this research show that the accumulation of the scores of 6 parameters were 47 points, it means that ITSB could receive the bronze category on Greenship Existing Building.
\end{abstract}

Keywords: global warming, greenship building, ITSB

\section{PENDAhUluan}

Ditinjau secara global, penghasil emisi gas rumah kaca terbesar berasal dari bangunan dengan persentase penggunaan $40 \%$ energi, $25 \%$ air, dan $40 \%$ sumber daya ${ }^{1)}$. Fakta yang sama terdapat di Amerika Serikat, $40 \%$ penghasil emisi gas rumah kaca berasal dari bangunan, dengan presentase melebihi emisi yang dihasilkan oleh sektor industri dan transportasi ${ }^{2)}$. Peningkatan emisi gas rumah kaca menyebabkan pemanasan global yang merupakan isu utama dunia karena berkaitan dengan lingkungan ${ }^{3)}$. Adanya pemanasan global menjadi tugas berat para ahli klimatilogi karena proses ini menyebabkan terjadinya peristiwa alam yang dapat membahayakan manusia dan sulitnya memprediksi ukuran emisi gas rumah kaca pada tahun-tahun selanjutnya ${ }^{4 ; 5)}$. Berbagai upaya telah dilakukan 
untuk mengurangi hal tersebut, salah satunya adalah penerapan konsep green building. Peneliti dan akademisi telah membahas green building dari perspektif teknis, keuangan, lingkungan hingga social ${ }^{6 ; 7}$. Selain itu langkah pengurangan emisi dilakukan melalui kebijakan dan regulasi yang telah dirumuskan dalam tiga dekade terakhir tentang konsep ramah lingkungan di dalam gedung ${ }^{8)}$.

Green building merupakan upaya untuk mengurangi dampak pemanasan global terhadap lingkungan dengan melakukan pembangunan gedung yang disesuaikan dengan konsep ramah lingkungan ${ }^{4 ; 9 ; 10)}$. Konsep green building dalam konstruksi berkelanjutan berkaitan dengan pengelolaan limbah, emisi, penggunaan energi terbarukan, bahan bebas racun ${ }^{11)}$. Dalam tahap operasi bangunan, green building merupakan pengembangan dari desain bangunan berkinerja tinggi yang mengutamakan penggunaan energi dan air untuk memerangi degradasi lingkungan, perubahan iklim, dan pengurangan sumber daya alam $^{12 ; 13,14)}$. Penerapannya dapat diukur dengan menggunakan penilaian khusus seperti ekologi, sosial, dan ekonomi ${ }^{15)}$.

Langkah nyata di Indonesia, pada tahun 2008 berdiri organisasi non profit Green Building Council Indonesia (GBCI) yang memiliki peran penting dalam penghematan penggunaan energi pada bangunan ${ }^{16)}$. GBCI mengungkapkan bahwa sektor bangunan memiliki potensi untuk membuat penghematan energi $50 \%$ atau lebih pada tahun 2050, untuk mendukung pembatasan kenaikan suhu global $2^{\circ} \mathrm{C}{ }^{17)}$. Sebagai bentuk dukungan terhadap pencegahan pemanasan global, Insitut Teknologi dan Sains Bandung (ITSB) menerapkan konsep green building dalam pembangunan gedung pendidikannya dan telah tersertifikasi oleh Green Building Council Indonesia $(G B C I)^{18)}$. Hal ini sesuai dengan visi ITSB untuk "Menjadi perguruan tinggi nasional terkemuka di bidang sains dan teknologi dengan menyelenggarakan pendidikan tinggi yang berorientasi pada industri berwawasan lingkungan” ${ }^{19)}$.

Sertifikat green building kategori New Building (NB) diterima oleh ITSB dengan perolehan 64 poin atau peringkat gold. Sertifikat tersebut berlaku selama tiga tahun sejak bulan April 2013 hingga April $2016{ }^{19}$. Oleh karena itu, untuk kembali mewujudkan visinya, pengelola gedung perlu melakukan evaluasi terhadap kondisi gedung, fasilitas dan lingkungan gedung sebelum melakukan sertifikasi ulang. Peneliti bermaksud melakukan evaluasi sederhana berkaitan dengan green building dari ITSB dengan tujuan untuk mengetahui kriteria penilaian resertifikasi, mengevaluasi kondisi existing gedung ITSB serta penyesuaiannya terhadap parameter penilaian, dan memberikan masukan terhadap manajemen gedung ITSB mengenai evaluasi resertifikasi green building. 


\section{METODE}

\subsection{Jenis Penelitian}

Jenis metode yang digunakan dalam penelitian ini adalah kualitatif. Metode kualitatif bertujuan untuk menjelaskan fenomena yang terjadi secara menyeluruh melalui pengumpulan data atau sampling ${ }^{20}$. Dalam penelitian ini, peneliti menggunakan metode kualitatif untuk mengetahui elemen green building yang terdapat pada parameter greenship existing building pada gedung ITSB. Objek penelitian yang diambil peneliti adalah gedung ITSB yang beralamat di Deltamas Lot-A-1 CBD, Jl. Ganesha Boulevard, Pasirranji, Cikarang Pusat, Bekasi, Jawa Barat.

\subsection{Sumber Data}

Sumber data diperoleh melalui dua cara, yaitu data primer dan data sekunder. Data primer yang didapatkan melalui instansi yang bersangkutan langsung dengan teknik observasi, wawancara dan kuisioner. Observasi yang dilakukan untuk mengamati enam parameter greenship existing building. Wawancara dilakukan oleh peneliti melalui narasumber yang pengelola gedung ITSB. Kuisioner digunakan untuk mempelajari tingkat kepuasan pengguna (dosen, karyawan, dan mahasiswa) terhadap gedung ITSB. Responden pengisian kuisioner diambil dengan menggunakan rumus slovin dan skala yang digunakan dalam penelitian ini adalah skala Likert. Data sekunder didapatkan melalui tinjauan dokumen yang terkait berupa jurnal, kajian, dan dokumen pengelolaan gedung.

\subsection{Teknik Analisi Data}

Teknik analisis data dalam penelitian ini menggunakan model analisa kualitatif deskriptif-evaluatif untuk mengetahui kondisi exsisting gedung ITSB terhadap enam parameter, mendeskripsikan kondisi exsisting tersebut, dan mengevaluasi dengan penilaian greenship existing buiding.

\section{PEMBAHASAN DAN DISKUSI}

\subsection{Hasil Penilaian Evaluasi terhadap Gedung ITSB}

Evaluasi penilaian terhadap gedung baru dan gedung lama ITSB terhadap kriteria sebagai green building yang sudah dilakukan peneliti dengan menggunakan enam parameter dari GBCI yaitu Tepat Guna Lahan - Appropriate Site Development (ASD), Efisiensi dan Konservasi Energi - Energy Efficiency \& Conservation (EEC), Konservasi Air - Water Conservation (WAC), Sumber \& Siklus Material - Material Resources \& Cycle $(M R C)$, Kualitas Udara \& Kenyamanan Udara Dalam Ruang - Indoor Air, Health \& Comfort (IHC) Manajemen Lingkungan Bangunan - Building \& Enviroment Management (BEM) melalui pelaksananaan wawancara dengan pengelola gedung, kuisioner yang disebarkan, dan studi literatur menghasilkan data yang dapat dilihat pada Gambar 1. 


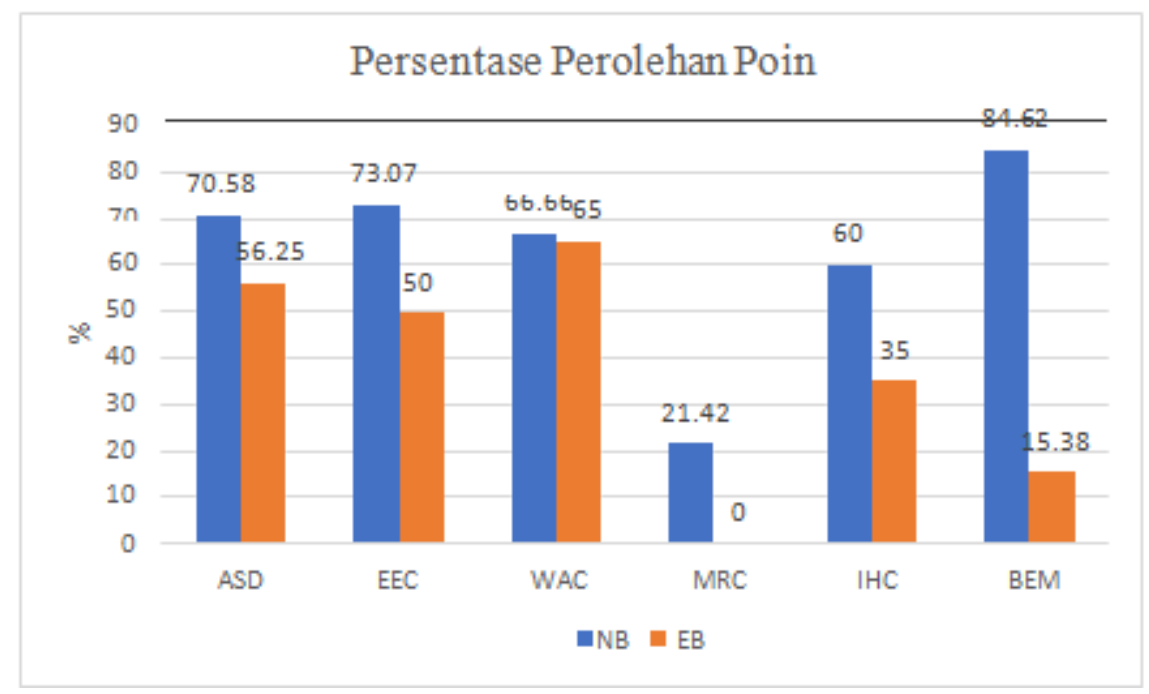

Gambar 1. Persentase perolehan poin penilaian green building terhadap enam parameter.

Parameter pertama yaitu kategori ASD Existing Building memperoleh sembilan poin dari total poin 16 atau sama dengan 56,25\%. Sedangkan untuk kategori ASD New Building memperoleh nilai 12 poin dari 17 poin atau sama dengan 70,58\%. Perbedaan ini disebabkan oleh kriteria ASD 6 Existing Building belum mendapat poin karena tidak menerapkan SPO, pengendalian hama penyakit tanaman masih menggunakan bahan-bahan yang beracun serta belum tersedianya habitat untuk satwa nonpeliharaan dengan minimal $15 \%$ dari seluruh area lahan bangunan. Selain itu, pada kriteria ASD 1 Existing Building belum menyediakan transportasi umum untuk pengguna gedung ITSB.

Parameter kedua yaitu kategori EEC New Building memperoleh 19 dari 26 poin atau 73,07\%. Sedangkan kriteria EEC Existing Building memperoleh 18 dari 36 poin atau 50\%. Perbedaan poin tersebut disebabkan oleh EEC New Building pada kriteria EEC 1 belum memperoleh poin maksimum karena perolehan penggunaan IKE gedung ITSB lebih kecil dari standar acuan (kantor $240 \mathrm{kWh} / \mathrm{m}^{2}$ ). Penghematan tersebut belum didukung dengan optimal seperti pada kategori EEC 2 yaitu melakukan Testing, Recommisioning or Retrocommisioning (TTR). Selain itu, pada katergori EEC 4 Existing Building belum menggunakan penerangan yang ramah lingkungan seperti $L E D$, dan pada kategori EEC 5 belum terdapat SPO yang jelas dari manajemen gedung mengenai operasi dan pemeliharaan sistem AC dan peralatan yang menggunakan sumber energi listrik lainnya.

Parameter ketiga yaitu kategori WAC New Building memperoleh 14 dari 21 total poin atau 66,66\% dan WAC Existing Building memperoleh 13 dari 20 poin atau 25\%. Pada WAC Existing Building terdapat prasyarat yang belum terpenuhi yaitu belum ada surat pernyataan yang memuat komitmen dari manajemen puncak yang berkaitan tentang monitoring, target penghematan dan action plan berjangka waktu tertentu oleh tim 
konservasi air serta belum ada kampanye dalam rangka mendorong konservasi air. Selain itu, pada kriteria WAC 3 Existing Building belum didukung dengan desain penghematan air seperti penurunan konsumsi air bersih, penggunaan water fixture yang belum sesuai dengan kapasitas buangan standar, belum ada penggunaan alternative water resource, belum ada instalasi penyimpanan air hujan. Selain itu, dari hasil wawancara dengan pengelola gedung dan juga arsip ITSB pada kriteria WAC 5 Existing Building belum ada inovasi filtrasi air, SPO pemeliharaan planning serta fitur auto stop.

Selanjutnya, parameter keempat yaitu kategori MRC New Building yaitu 3 dari 14 total poin atau 21,43\% dan MRC Existing Building yaitu 0 dari 12 total poin atau $0 \%$. Kriteria $M R C$ diambil dari non UDS usage pembelian material yang ramah lingkungan serta pengolahan sampah berdasarkan 3R. Pada kriteria MRC $2 \mathrm{New}$ Building mendapat poin karenaa menggunakan Regional Material serta Certified Wood . Namun, pada MRC 2 Existing Building belum dapat dipenuhi karena tidak memiliki SPO mengenai material ramah lingkungan, sehingga penggunaan material ramah lingkungan pada saat awal pembangunan belum sustainable terhadap management building sampai dengan tahun 2019.

Parameter yang kelima yaitu kategori IHC Existing Building mendapat poin 6 dari 20 total poin atau 30\% dan IHC New Building memperoleh 6 dari total 10 poin atau $60 \%$. Perbedaan persentase pada kedua kategori tersebut yaitu 30\% karena terdapat prasyarat yang belum terpenuhi secara menyeluruh sebagai contoh yaitu belum adanya kampanye yang mencakup akibat negatif bahaya merokok. Pada kriteria IHC New Building, gedung ITSB telah menggunakan $\mathrm{CO}^{2}$ monitoring serta menerapkan pelarangan merokok di dalam area gedung, sedangkan pada IHC Existing Building masih terdapat ruang untuk merokok terutama pada area kantin gedung ITSB serta penggunaan $\mathrm{CO}^{2}$ pada ruang dengan kepadatan tinggi sudah tidak dilakukan karea keberadaan alat tersebut di ruang rektorat tidak dapat bekerja sesuai fungsinya dan alat monitoring pada ruang aula sudah tidak dapat digunakan. Terdapat kriteria pada IHC New Building yang tidak terpenuhi yaitu kesehatan dalam ruangan yang kurang berkaitan dengan chemical pollutan yang juga terjadi pada IHC Existing Building.

Penilaian kriteria tersebut juga didapat dari hasil kuisioner kenyamanan pengguna gedung dengan sampel $30 \%$ orang dari total pengguna gedung baik mahasiswa, dosen, dan karyawan dengan identitas yang dapat dilihat di Tabel 1. Dari 88 responden tersebut hasilnya dapat dilihat pada Gambar 2. 
Tabel 1. Identitas Responden

\begin{tabular}{lll}
\hline Jenis kelamin & - Perempuan & 52 orang / 47,2\% \\
& - Laki-laki & 58 orang / 52,8\% \\
\hline Umur & $-18-26$ thn & 101 orang/91,9\% \\
& $-27-35$ thn & 8 orang / 7,3\% \\
& $-36-44$ thn & 1 orang / 0,8\% \\
\hline Profesi & - Dosen & 4 orang \\
& - Karyawan & 7 orang \\
& - Mahasiswa & 99 orang \\
\hline
\end{tabular}

\section{Hasil Kuisioner Kenyamanan Responden}

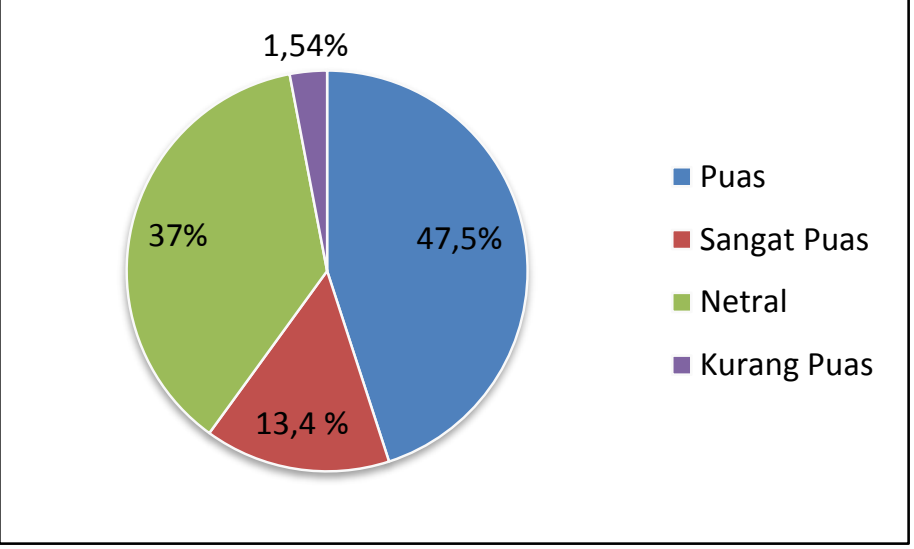

Gambar 2. Hasil kuisioner kenyamanan responden

Hasil pada Gambar 2 menunjukkan dalam pengukuran kenyamanan gedung ITSB sebanyak 47,5\% merasa puas terhadap kenyamanan dari gedung ITSB, 13,4\% merasa sangan puas. Akumulasi persentase tersebut menunjukan bahwa $60,9 \%$ responden merasa nyaman berada dalam ruangan gedung ITSB. Sementara responden yang menjawab netral ada pada persentase 37\%, hal ini mengindikasikan sebagian dari responden tidak mempermasalahkan keadaan kenyamanan dalam ruang. Selanjutnya, persentase kurang puas sebesar 1, 54\% dan sangat tidak puas sebesar $0 \%$. Berdasarkan analisa dari persentase tersebut dapat diketahui bahwa $60,9 \%$ pengguna gedung ITSB merasa nyaman karena dapat mendukung aktivitas mereka dalam gedung sehingga pengguna gedung dapat lebih berkonsentrasi dalam melakukan aktivitasnya masing-masing.

Terakhir, pada parameter keenam yaitu kategori BEM New Building mendapat 11 poin dari 13 poin atau 84,6\% dan BEM Existing Building mendapat 2 dari 13 poin atau 15,38\% poin. Kecilnya persentase yang dihasilkan oleh BEM Existing Building disebabkan oleh belum adanya rencana operasi dan pemeliharaan untuk mencapai rating-rating Greenship Existing Building. 
Hasil akumulasi penilaian evaluasi dari kondisi Existing dan New Buildings terhadap Greenship Existing Building Memperoleh menunjukkan bahwa ITSB memperoleh peringkat bronze dengan perolehan poin yaitu 47 dengan penjabaran kriteria ASD yaitu 9 poin atau $56,25 \%$, kriteria $E E C$ memperoleh 18 poin atau sebesar $50 \%$, kriteria WAC memperoleh 13 poin atau sebesar $65 \%$, kriteria $M R C$ memperoleh 0 poin atau sebesar $0 \%$, kriteria $I H C$ memperoleh 7 poin atau sebesar 35\%, kriteria BEM memperoleh 2 poin atau sebesar $15,38 \%$.

\section{KESIMPULAN}

Berdasarkan hasil penelitian dan pembahasan sebelumnya, dapat disimpulkan bahwa ITSB memperoleh poin 47 dari hasil rating kondisi existing terhadap greenship existing building atau peringkat bronze dengan penjabaran kriteria $A S D 9$ poin atau 56,25\%, kriteria $E E C 18$ poin atau $50 \%$, kriteria $W A C 13$ poin atau $65 \%$, kriteria $M R C 0$ poin atau $0 \%$, kriteria IHC 7 poin atau 35\%, kriteria BEM 2 poin atau 15,38\%. Hasil perhitungan rating terhadap kondisi existing tersebut dipengaruhi oleh hasil perolehan poin pada sertifikasi new building.

Rekomendasi dari peneliti yaitu perlu dilakukan perbaikan pengelolaan pada tiga parameter penilaian, yaitu $M R C, I H C$, dan BEM apabila ITSB akan melakukan sertifikasi ulang. Pertama, pada parameter $M R C$ perlu diperbaiki pada bagian pengelolaan AC, daur ulang sampah sesuai $3 R$, dan pengurangan penggunaan plastik. Kedua, berkaitan parameter $I H C$ perlu adanya edukasi larangan merokok secara luas di lingkungan kampus. Sedangkan, untuk parameter BEM, perlu adanya pembuatan dokumen berkaitan dengan green building secara lengkap dan pembuatan jadwal pengelolaan gedung yang tepat.

\section{UCAPAN TERIMA KASIH}

Penulis mengucapkan terima kasih kepada ITSB dan $G B C I$, yang mendukung penelitian ini sehingga dapat diselesaikan dengan baik.

\section{DAFTAR PUSTAKA}

1) UNEP, F. (2009). Fiduciary responsibility: Legal and practical aspects of integrating environmental, social and governance issues into institutional investment. UNEP FI: Geneva.

2) Council, U. G. B. (2016). Benefits of green building. US Green Building Council, 1.

3) Inayati, I., Soelami, F. X. N., \& Triyogo, R. (2017). Identification of existing office buildings potential to become green buildings in energy efficiency aspect. Procedia engineering, 170, 320-324Shahzad, U. (2015). Global Warming: Causes, Effects and Solutions. Lincoln: University of Nebraska

4) UNEP-WCMC, I. U. C. N. (2016). Protected planet report 2016. UNEP-WCMC and IUCN: Cambridge UK and Gland, Switzerland, 78-95. 
5) Rogelj, J., Den Elzen, M., Höhne, N., Fransen, T., Fekete, H., Winkler, H., ... \& Meinshausen, M. (2016). Paris Agreement climate proposals need a boost to keep warming well below 2 C. Nature, 534(7609), 631-639.

6) Medineckiene, M., Zavadskas, E. K., Björk, F., \& Turskis, Z. (2015). Multi-criteria decision-making system for sustainable building assessment/certification. Archives of Civil and Mechanical Engineering, 15(1), 11-18.

7) Shad, R., Khorrami, M., \& Ghaemi, M. (2017). Developing an Iranian green building assessment tool using decision making methods and geographical information system: Case study in Mashhad city. Renewable and Sustainable Energy Reviews, 67, 324340.

8) Trencher, G., Broto, V. C., Takagi, T., Sprigings, Z., Nishida, Y., \& Yarime, M. (2016). Innovative policy practices to advance building energy efficiency and retrofitting: Approaches, impacts and challenges in ten C40 cities. Environmental Science \& Policy, 66, 353-365.

9) Ramírez-Villegas, R., Eriksson, O., \& Olofsson, T. (2016). Assessment of renovation measures for a dwelling area-Impacts on energy efficiency and building certification. Building and Environment, 97, 26-33.

10) Aktas, B., \& Ozorhon, B. (2015). Green building certification process of existing buildings in developing countries: cases from Turkey. Journal of Management in Engineering, 31(6), 05015002.

11) Shi, Q., Zuo, J., Huang, R., Huang, J., \& Pullen, S. (2013). Identifying the critical factors for green construction-an empirical study in China. Habitat international, 40, 18.

12) Bauer, M., Mösle, P., \& Schwarz, M. (2009). Green building: guidebook for sustainable architecture. Springer Science \& Business Media.

13) Elshimy, H. (2015). Green building as concept of sustainability Sustainable strategy to design Office Building. Alexandria: Pharos University.

14) Kibert, C. J. (2016). Sustainable construction: green building design and delivery. John Wiley \& Sons.

15) Berawi, M. A., Miraj, P., Windrayani, R., \& Berawi, A. R. B. (2019). Stakeholders' perspectives on green building rating: A case study in Indonesia. Heliyon, 5(3), e01328.

16) Wimala, M., Akmalah, E., \& Sururi, M. R. (2016). Breaking through the barriers to green building movement in Indonesia: Insights from building occupants. Energy Procedia, 100(100), 469-474.

17) Green Building Council Indonesia. http://gbcindonesia.org/. (diakses: 17 Feb. 2020)

18) Green Building Council Indonesia. http://gbcindonesia.org/. (diakses: 17 Feb. 2020)

19) Institut Teknologi Sains Bandung. https://www.itsb.ac.id/. (diakses: 17 Feb. 2020)

20) Sugiyono. (2017). Metode Penelitian Kualitatif, Kuantitatif, dan RnD. Bandung: Alfabeta. 